\title{
Sickle cell disease in Nigerian children: A cross-sectional study on parental awareness and home management of pain
}

\author{
Oyetundun Fausat Afolabi, ${ }^{1}$ Sabastine Ndubisi Esomonu ${ }^{2}$ \\ ${ }^{1}$ Department of Paediatrics, General Hospital, Bwari; ${ }^{2}$ Federal Capital Territory Primary Health Care \\ Board, Garki, Federal Capital Territory (FCT), Nigeria
}

\begin{abstract}
Pain, being the clinical trademark of Sickle Cell Disease (SCD), impacts negatively on clinical outcome in children. However, little is known regarding parental home pain management in children with SCD. We aimed to determine the parental awareness, use and perceived efficacy of pain relief techniques for children with SCD. This is a cross-sectional study involving 80
\end{abstract}

Correspondence: Oyetundun Fausat Afolabi, Department of Paediatrics, General Hospital, Bwari, PMB 72, Kawo Road, Bwari, Federal Capital Territory, Nigeria.

E-mail: oyetundun4real@yahoo.com

Tel.: +2348035859724

Key words: Sickle cell disease; children; pain; home management

Acknowledgement: The authors would like to appreciate the respondents for their cooperation in this study.

Contributions: AOF: Conception, design, data analysis and interpretation, drafting of manuscript and review, final approval of manuscript, agreement of its contents. ESN: Design, data analysis and interpretation, drafting and review of manuscript, final approval of manuscript, agreement of its contents.

Conflict of interest: The authors declare no conflict of interest.

Availability of data and materials: All data generated or analyzed in this study are presented in the article.

Ethical approval and consent to participate: Ethical approval was obtained from the Health Research Ethics Committee (HREC) of the Federal Capital Territory Administration (FCTA) [Approval Number: FHREC/2019/01/42/30-04-19]. A written informed consent was obtained from the study participants before enrolment.

Consent for publication: The study participants gave their consent to the publication of the results presented in this paper.

Received for publication: 11 January 2021.

Revision received: 15 March 2021.

Accepted for publication: 26 March 2021.

This work is licensed under a Creative Commons Attribution NonCommercial 4.0 License (CC BY-NC 4.0).

${ }^{\circ}$ Copyright: the Author(s), 2021

Licensee PAGEPress, Italy

Annals of Clinical and Biomedical Research 2021; 2:131

doi:10.4081/acbr.2021.131 parents of children with SCD seen at General Hospital, Bwari, North-Central Nigeria. An interview-based, structured questionnaire was used to obtain information on socio-demographic characteristics, clinical history, parental awareness, use and perceived effectiveness of pain relief techniques. Data analysis was with SPSS version 20. Seventy-six $(95.0 \%)$ respondents were aware of available pain relief technique(s) in SCD. Fifty-four $(67.5 \%)$ respondents used pain relief techniques, $33(61.1 \%)$ of whom used multiple pain relief techniques. The most commonly used drugs and Complementary and Alternative Medicine (CAM) were nonsteroidal anti-inflammatory drugs $(47.0 \%)$ and massage $(36.0 \%)$ respectively. Thirty-three $(61.1 \%)$ respondents perceived their selected techniques as effective. A higher proportion $(27.3 \%)$ of the children with multiple hospitalizations used multiple pain relief techniques when compared with $4.8 \%$ who used drugs alone $(p=0.038)$. However, there was no significant difference based on age, gender, maternal education, genotype, age at diagnosis, pain episodes, regularity of routine drugs and packed cell volume of the children and pain relief techniques used $(p>0.05)$. This study found high parental awareness and utilization of home pain relief techniques for children with SCD. The use of multiple pain relief techniques was influenced by multiple hospitalizations of the children.

\section{Introduction}

Sickle Cell Disease (SCD) is a genetic hematological disorder inherited as an autosomal recessive Mendelian trait and characterized by the presence of abnormal Haemoglobin (Haemoglobin S) in the Red Blood Cells (RBCs). ${ }^{1,2}$ Whilst SCD encompasses all disorders with the phenomenon of red cell sickling, the most common and severe form, sickle cell anaemia, connotes homozygosity for Haemoglobin S (HbSS). 2,3 Globally, over 300,000 newborns are affected by this disorder annually, with about $76 \%$ occurring in Sub-Saharan Africa alone. ${ }^{2,4,5}$ This percentage is projected to increase to $88 \%$ by the year 2050 , thereby constituting a major public health concern. ${ }^{5}$ Nigeria, being the most populous country in Africa, has the highest burden of children with SCD worldwide, with reported prevalence of $2-5 \%$ of population. ${ }^{6-8}$ Furthermore, about $50-80 \%$ of affected children die of complications before five years of age due to limited resources available to provide the complex care required for them. ${ }^{1-3}$

Amongst other complications, persons living with SCD experience pain which has been found to be the most consistent and characteristic feature. ${ }^{9-11}$ The spectrum of clinical expression is however heterogenous, varying in intensity, frequency, duration and affected sites. ${ }^{3,9,12}$ Pain in SCD is classified as episodic (acute) or persisting (chronic).$^{9-13}$ Episodic pain occurs during vaso-occlusive events due to activation of nociceptive nerve endings in ischaemic bones or the mesenteric vessels of the abdomen. ${ }^{9,10,12,13}$ On the other hand, persisting pain can result from tissue damage due to avascular necrosis or chronic leg ulcers, as well as subopti- 
mal treatment of recurrent acute painful episodes. ${ }^{9,12}$ While episodic pain is commoner in younger children, adolescents tend to experience more of persisting pain. ${ }^{11,12}$ The attendant negative consequences associated with these painful episodes include decreased school attendance, social functioning, physical activity/mobility and negative psychosocial consequences. ${ }^{10-12,14}$

One of the core principles of management of pain in SCD include adequate analgesia with drugs such as paracetamol (acetaminophen), Non-Steroidal Anti-Inflammatory Drugs (NSAIDS) and opioids. ${ }^{3,9,12,15}$ Recent guidelines on pain management have also recommended the use of non-pharmacologic methods including Complementary and Alternative Medicine (CAM) ${ }^{15,16}$ Furthermore, it is recommended that mild to moderate painful episodes can be managed at home, while severe episodes require hospitalization and use of parenteral analgesia. ${ }^{9,12,13}$ Even though a lot of pain episodes are initially managed at home, there is paucity of literature regarding caregiver home management of SCD-related pain in the paediatric age group. More attention is however focused on SCD pain management in hospital settings. ${ }^{17,18}$ Furthermore, exploring the various caregiver pain management techniques and their perceived efficacy in Nigerian children with SCD would not be amiss as this may help in targeted counseling for integrated pain alleviation or otherwise, thereby ensuring improved quality of life.

\section{Materials and Methods}

\section{Study design}

This was a descriptive, cross-sectional, hospital-based study of parents/caregivers of children with Sickle Cell Disease aged one to fifteen years and seen at the General Hospital, Bwari. Subjects were recruited over a period of four months (June to September, 2019). All parents/caregivers of eligible children were briefed about the purpose of the study, after which written consents were obtained. Ethical approval was obtained from the Health Research Ethics Committee (HREC) of the Federal Capital Territory Administration (FCTA).

\section{Study location}

The study was conducted at the General Hospital, Bwari, one of the fourteen public secondary health facilities located in the Federal Capital Territory (FCT), North-Central, Nigeria. The hospital is situated in Bwari town within Bwari Area Council of the FCT, with an estimated population of $365,007 .{ }^{19}$ Bwari General Hospital offers Paediatric Emergency, in-patient and out-patient services, with an average monthly visits of 1,500 patients. The Paediatric Department of the hospital also offers specialist clinic services including the SCD clinic which is run once weekly for children with SCD aged fifteen years and below, and has an average monthly attendance of 35 patients. Every medical consultation involves history taking, physical examination, routine Packed Cell Volume (PCV) estimation with or without other investigations deemed necessary, and refill of routine drugs.

\section{Study procedures}

Eighty parents/caregivers of children with SCD aged one to fifteen years presenting to the Paediatric SCD and/or out-patient clinic and the emergency unit of the hospital for medical consultation were recruited. Caregivers were defined as those under whose care the index child has been for at least one year. Parents/caregivers who are skilled health workers (doctors, nurses and pharma- cists), and those whose children required urgent referral or those who did not consent to participation in the study, were excluded from the study.

Data was obtained by the researchers from the respondents using an interviewer-administered, structured questionnaire. The questionnaire comprised of five domains namely: socio-demographic characteristics (viz: children's age and sex, maternal education, number of children in the family) and the Socio-Economic Status (SES) assessed using the father's occupation and the maternal educational attainment as proposed by Olusanya et al. ${ }^{20}$ This method stratifies the SES into upper (classes I and II), middle (Class III) and lower (Classes IV and V); SCD history of the child [viz: genotype, age at diagnosis, frequency of hospital admissions/year, frequency of pain episodes/month, regularity of use of routine drugs, and Packed Cell Volume (PCV) obtained from the present medical consultation]; parental awareness regarding pain in SCD; parental home management of pain; and perceived effectiveness of current home pain management. For data quality assurance, the structured questionnaire was pretested and appropriate modifications were made prior commencement of the study.

The minimum sample size required for this study was determined using the formula for single population proportion ${ }^{21}$ as follows:

$\mathrm{n}=\frac{\mathrm{Z}^{2} \times \mathrm{P}(1-\mathrm{P})}{\mathrm{d}^{2}}$

where $\mathrm{n}$ is the minimum sample size required for the study; $\mathrm{d}$ is $5 \%$ margin of error $=0.05 ; \mathrm{Z}$ is value of standard normal distribution $(\mathrm{Z}=1.96)$ with confidence interval of $95 \%$; and $\mathrm{P}=$ prevalence of $\operatorname{SCD}(5 \%){ }^{8}$

Therefore,

$\mathrm{n}=\frac{(1.96)^{2} \times 0.05(1-0.05)}{(0.05)^{2}}=73$

This gave the minimum sample size, $\mathrm{n}=73$. Allowing for $10 \%$ attrition rate, the final sample size became 80 . The study participants were recruited consecutively until the desired sample size was achieved.

\section{Data analysis}

Data was analyzed using the Statistical Package for Social Sciences (SPSS) version 20.0 software (IBM Corp., Armonk, NY, USA). Measures of central tendency for quantitative variables, as well as frequencies and proportions for qualitative variables were obtained. The Chi-square test was used to measure association between dependent and independent variables. Binary logistic regression was used to determine socio-demographic and other predictors of multiple pain relief techniques, which is measured as the combination of conventional drugs and CAM use in this study. Variables at $95 \%$ of confidence interval and the $p$ value of $<0.05$ were considered significant.

\section{Results}

\section{Sample Demographics and SCD History}

A total of 80 respondents were investigated. The respondents ranged in age from 18 to 64 years. Sixty-eight $(85.0 \%)$ of the respondents were mothers, while $39(48.8 \%)$ belonged to the middle social class. Fifty-nine $(73.7 \%)$ of the children were aged 
above five years, with mean age of $7.8 \pm 3.5$ years. Reflecting the distribution found in the general population, $76(95.0 \%)$ of the children had genotype SS. Fifty-six $(70.0 \%)$ were diagnosed by two years of age. However, a total of $12(15.0 \%)$ and $19(23.8 \%)$ had greater than two admissions/year and three or more pain episodes/ month respectively. Additional information about the sample population is as illustrated in Table 1.

\section{Parental awareness and knowledge of pain relief tech- niques}

The Venn diagram (Figure 1) shows that 39 (48.8\%) of the respondents knew the techniques of medications and CAM for pain relief, while $35(43.7 \%)$ knew medications as the only means of pain relief. Respondents who knew only CAM as pain relief

Table 1. Demographic characteristics and SCD history of the study population.

\begin{tabular}{lcc}
$\begin{array}{l}\text { Variables } \\
\text { Children's age (years) }\end{array}$ & $\begin{array}{c}\text { Frequency } \\
(\mathrm{N}=80)\end{array}$ & $\begin{array}{c}\text { Percentage } \\
(\%)\end{array}$ \\
$\leq 5$ & 21 & 26.3 \\
$6-10$ & 43 & 53.7 \\
\hline $11-15$ & 16 & 20.0 \\
Children's gender & & \\
M & 49 & 61.2 \\
F & 31 & 38.8 \\
\hline Socioeconomic status & & \\
\hline Lower (IV \& V) & 13 & 16.2 \\
Middle (III) & 39 & 48.8 \\
\hline Upper (I \& II) & 28 & 35.0 \\
Respondents' relationship to child & & \\
Mother & 68 & 85.0 \\
Father & 9 & 11.2 \\
\hline Others & 3 & 3.8 \\
Genotype & & \\
SS & 76 & 95.0 \\
Others & 4 & 5.0 \\
\hline Age at diagnosis (years) & & \\
\hline
\end{tabular}

Age at diagnosis (years)

\begin{tabular}{lll}
$\leq 2$ & 56 & 70.0 \\
\hline 2 & 24 & 30.0 \\
Hospital admissions/year & & \\
$\leq 2$ & 68 & 85.0 \\
$>2$ & 12 & 15.0 \\
\hline
\end{tabular}

\begin{tabular}{lll} 
Pain episodes/month & & \\
$<3$ Episodes & 61 & 76.2 \\
\hline$\geq 3$ Episodes & 19 & 23.8 \\
Regularity of routine drugs & & \\
Yes & 62 & 77.5 \\
No & 18 & 22.5 \\
\hline Latest PCV & &
\end{tabular}

\begin{tabular}{lrc} 
Mild anemia $(32-30 \%)$ & 2 & 2.5 \\
Moderate anemia $(29-21 \%)$ & 51 & 63.7 \\
\hline Severe anemia $(<21 \%)$ & 27 & 33.8 \\
\hline
\end{tabular}

techniques were two (2.5\%), while 4 (5.0\%) had no idea of type of pain relief used during pain episodes. Figure 2 illustrates the respondents' knowledge of CAM as pain relief techniques. Massage was the commonest form of CAM for pain relief known to the respondents' $(40.0 \%)$, followed by prayers $(32.6 \%)$, while only one respondent $(1.1 \%)$ knew relaxation as CAM for pain relief.

\section{Parental practice and perceived effectiveness of pain management}

Fifty-four of the 80 respondents $(67.5 \%)$ reported use of home pain relief for their child's pain episodes over the past six months. Among the 54 parents, 33 (61.1\%) used multiple pain relief techniques (drugs and CAM). Non-Steroidal Anti-Inflammatory Drugs (NSAIDs) were the commonest group of drugs used $(47.0 \%)$, while Massage was the commonest CAM used by the respondents $(50.0 \%)$. Thirty-three $(61.1 \%)$ of the 54 respondents who practiced home pain management believed that the techniques were effective (Table 2). Table 3 shows the relationship between perceived effectiveness of home pain management and the technique used. A higher proportion of parents who used drugs alone for home pain

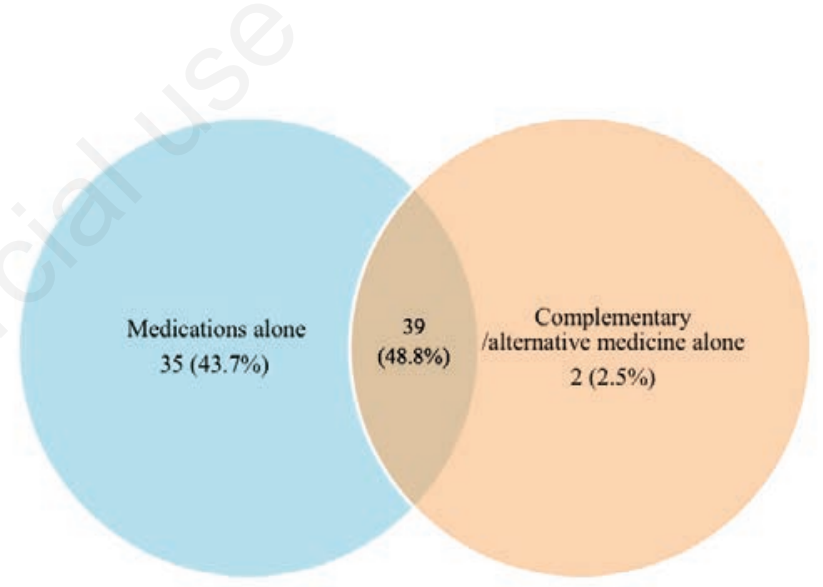

Figure 1. Respondents' knowledge of pain relief techniques in SCD.

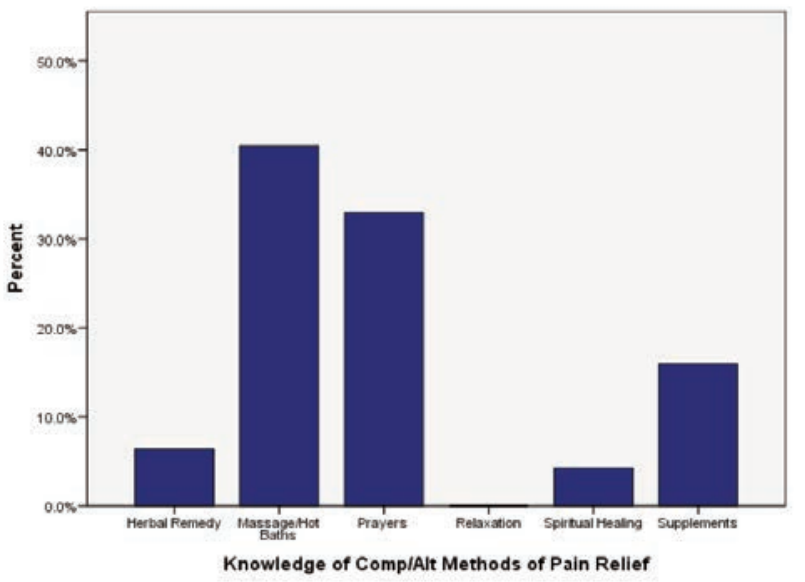

Figure 2. Knowledge of complementary/alternative methods of pain relief. 
management (66.7\%) had good perception of effectiveness of home pain management than those who used drugs and other methods $(57.6 \%)$, but the difference in proportions was not statistically significant $(\mathrm{p}=0.504)$.

\section{Pain relief techniques and selected parameters}

Table 4 shows that index children aged five years and below had a higher proportion (27.3\%) and slightly higher odds of using multiple pain relief techniques (drugs and CAM) for home pain management when compared with children above five years of age. However, the difference was not statistically significant $(p=0.777)$. Similarly, the maternal education, gender, genotype, age at diagnosis, number of pain episodes per month, regularity of routine drugs, as well as the latest PCV of the index children did not significantly influence the use of multiple pain relief techniques $(\mathrm{p}>0.05)$.

Table 2. Parental home management of pain.

\begin{tabular}{l} 
Variables $\begin{array}{c}\text { Frequency Percentage } \\
(\mathbb{N}=80)\end{array}$ \\
\hline
\end{tabular}

Use of home pain relief over last 6 months

\begin{tabular}{lll} 
Yes & 54 & 67.5 \\
\hline No & 26 & 32.5
\end{tabular}

\begin{tabular}{lcc}
\hline If yes, kind of pain relief techniques used & $(\mathbf{N}=54)$ & $(\%)$ \\
Drugs alone & 21 & 38.9 \\
Both Drugs and CAM & 33 & 61.1 \\
\hline Drugs used for pain relief (multiple responses) & \\
NSAIDS (Ibuprofen, Diclofenac etc) & 32 & 47.0 \\
PCM & 31 & 45.6 \\
\hline Opioids & 1 & 1.5 \\
Others & 4 & 5.9 \\
\hline Selected CAM used for pain relief (multiple responses)
\end{tabular}

\begin{tabular}{lcc} 
Massage & 27 & 50.0 \\
Prayer & 17 & 31.4 \\
\hline Spiritual healing & 3 & 5.6 \\
Herbal remedies & 3 & 5.6 \\
\hline Supplements & 3 & 5.6 \\
Others & 1 & 1.8 \\
\hline Perceived effectiveness of home pain management
\end{tabular}

Effective (pain mostly resolves at home) $\quad 33 \quad 61.1$

Not effective (mostly requires hospital admission) $\quad 21 \quad 38.9$
However, a significantly higher proportion $(27.3 \%)$ of the index children who were hospitalized more than twice a year managed their pain episodes with multiple pain relief techniques when compared with $4.8 \%$ who used drugs alone as pain relief techniques $(\mathrm{p}=0.038)$.

\section{Discussion}

This study aimed at evaluating parental awareness, knowledge and home pain management of Nigerian children with SCD. We further explored the relationship between the pain relief techniques employed and parents' perceived effectiveness, as well as its relationship with selected socio-demographic and other parameters. Expectedly, $95 \%$ of the respondents knew one form of pain relief technique or the other, which underscores the prominence of pain as a symptom of SCD. Being the commonest symptom experienced by sufferers, most parents/caregivers would employ any known measure to alleviate or halt the progression of pain so as to relieve discomfort and avoid hospitalization, which could be distressing to the child and family. Alongside medication use, about half of the respondents knew various forms of CAM as means of pain relief, lending further credence to an increasing recognition of CAM use in this part of the world which is consistent with global trends. ${ }^{22}$

Data analysis also indicates that about two out of three parents reported use of home pain relief techniques for their children's pain episodes over the past six months, majority of whom $(61.1 \%)$ used a combination of orthodox drugs and CAM. In tandem with other studies that investigated paediatric SCD population, ${ }^{23,24}$ our findings on CAM utilization are much lower than the reported prevalence from adult SCD population. ${ }^{25-27}$ This may be due to children's inability to take decisions on their own health care, thereby relying on adults for choice of pain relief. Furthermore, a higher percentage of adults with SCD experience chronic, debilitating pain which may prompt them to seek alternative means of pain control. ${ }^{9,11,26}$

The use of Non-steroidal anti-inflammatory drugs (NSAIDs) as the medication for pain relief were in the majority $(47.0 \%)$ in this study, which is not surprising, given its proven efficacy and recommendation for use in mild to moderate painful episodes. . $^{3,12,15,16}$ On the other hand, it was found that massage was the most frequently used CAM among the respondents $(50.0 \%)$. Although with prevalence rates of $14-67 \%$ reported by previous studies, massage was one of the leading CAM employed for pain relief in SCD. ${ }^{26-28}$ On the contrary, prevalence rates of $2.0 \%$ and $4.0 \%$ reported in studies carried out in Lagos, South-west Nigeria indicate a low utilization of massage in that region, with predominance of biological products' as CAM. ${ }^{25,29}$

It is also noteworthy that, unlike studies from other parts of the world, none of the respondents in our study admitted to use of cer-

Table 3. Relationship between perceived effectiveness of home pain management and the technique used.

Technique used for home pain management
Perceived effectiveness of home $\quad$ Drug use alone $\quad$ Drug use and CAM
n $(\%)$

Pain management

\begin{tabular}{|c|c|c|c|}
\hline Effective & $14(66.7)$ & $19(57.6)$ & 0.446 \\
\hline Not effective & $7(33.3)$ & $14(42.4)$ & \\
\hline
\end{tabular}


tain types of CAM such as acupuncture, hypnosis, homeopathy, biofeedback, and other cognitive strategies. ${ }^{26-28}$ The reason adduced to this disparity include unfamiliarity to certain types of $\mathrm{CAM}$, as culture, health beliefs and religious underpinnings may influence preference of type of CAM. ${ }^{25}$ In addition, the lack of access to professional services for certain CAM such as acupuncture, as well as patients in the paediatric age group could be barriers in the utilization of some forms of CAM.

The descriptive information from this study shows that $61.1 \%$ of the respondents adjudged their current home pain relief strategy as effective, indicating that most pain episodes reduce or resolve without resulting in hospital visits/admission. This compares well with previous reports evaluating patient-perceived benefits of pain relief, particularly with use of CAM in conjunction with conventional treatment of SCD. ${ }^{25,28}$ However, this study found that the respondents' perception of effectiveness occurred irrespective of whether drugs were used alone, or in combination with CAM as relief for pain episodes. This finding also puts to question the additional benefits of some forms of CAM, particularly massage whose beneficial effects evaluated by previous studies were conflicting, probably due to application by patients and relatives who are mostly non-professionals. ${ }^{30}$ Moreover, the long term efficacy of CAM cannot be reflected in our findings given the study period.

In this study, the use of multiple pain techniques for pain relief was not significantly influenced by socio-demographic characteristics such as age, gender, maternal education and genotype of the index children. This is in congruence with findings from previous studies which evaluated the influence of CAM utilization for pain in SCD. ${ }^{25-27}$ Busari et al. reported that age, gender, genotype, level of education and a stable haemoglobin concentration $>7 \mathrm{~g} / \mathrm{dl}$ did not significantly influence CAM use, although respondents who were Christians and of Yoruba ethnicity were more likely to use CAM. ${ }^{25}$ In another study by Thompson et al., there was no significant influence of age, marital status and genotype on CAM use, but noted that males and those with less than high school education were less likely to use CAM for relief of pain episodes. ${ }^{27}$ On the other hand, Majumdar et al. documented a significant association of marital status with relaxation therapy, as well as age and level of education with use of prayer. $^{26}$

Against the background of dearth of studies documenting the relationship between pain relief techniques and patient SCD history, this study observed that a significantly higher number of children who were admitted twice or more times a year used multiple pain relief techniques for home pain relief. This is in consonance with reports by Sibinga et al. in which CAM use was associated with SCD severity, particularly multiple hospitalization. ${ }^{23}$ However, the use of single or multiple pain relief techniques were comparable irrespective of factors such as age at diagnosis, number of pain episodes per month, and regularity of routine drugs. In view of paucity of published studies, further studies will be needed to disprove, or otherwise, the influence of patient SCD history on the choice of use of pain relief techniques.

Table 4. Relationship between pain relief techniques and selected parameters.

\begin{tabular}{|c|c|c|c|c|}
\hline Variables & $\begin{array}{l}\text { Pain Relis } \\
\text { (n } \\
\text { Drugs alone } \\
\text { n (\%) }\end{array}$ & $\begin{array}{l}\text { que } \\
\text { Drugs and CAM } \\
\text { n }(\%)\end{array}$ & $\begin{array}{c}\text { P-value on bivariate } \\
\text { analysis }\end{array}$ & $\begin{array}{l}\text { AOR }(95 \% \mathrm{CI}) \text { on } \\
\text { multivariate analysis }\end{array}$ \\
\hline $\begin{array}{l}\text { Age of child (years) } \\
\leq 5 \\
>5\end{array}$ & $\begin{array}{c}5(23.8) \\
16(76.2)\end{array}$ & $\begin{array}{c}9(27.3) \\
24(72.7)\end{array}$ & 0.777 & $1.663(0.354-7.801)$ \\
\hline $\begin{array}{l}\text { Gender of child } \\
\text { Male } \\
\text { Female }\end{array}$ & $\begin{array}{c}7(33.3) \\
14(66.7)\end{array}$ & $\begin{array}{l}14(42.4) \\
19(57.6)\end{array}$ & 0.504 & $2.391(0.567-10.083)$ \\
\hline $\begin{array}{l}\text { Maternal education } \\
<\text { High school (SSCE) } \\
\geq \text { High school (SSCE) }\end{array}$ & $\begin{array}{c}3(14.3) \\
18(85.7)\end{array}$ & $\begin{array}{l}10(30.3) \\
23(69.7)\end{array}$ & 0.180 & $2.299(0.383-13.802)$ \\
\hline $\begin{array}{l}\text { Genotype } \\
\text { SS } \\
\text { Others }\end{array}$ & $\begin{array}{c}20(95.2) \\
1(4.8)\end{array}$ & $\begin{array}{c}31(93.9) \\
2(6.1)\end{array}$ & 0.839 & $1.317(0.066-26.342)$ \\
\hline $\begin{array}{l}\text { Age at diagnosis (years) } \\
\leq 2 \\
>2\end{array}$ & $\begin{array}{c}15(71.4) \\
6(28.6)\end{array}$ & $\begin{array}{l}23(69.7) \\
10(30.3)\end{array}$ & 0.892 & $0.433(0.081-2.333)$ \\
\hline $\begin{array}{l}\text { Hospital Admissions/year } \\
\leq 2 \\
>2\end{array}$ & $\begin{array}{c}20(95.2) \\
1(4.8)\end{array}$ & $\begin{array}{r}24(72.7) \\
9(27.3)\end{array}$ & 0.038 & $0.098(0.008-1.238)$ \\
\hline $\begin{array}{l}\text { Pain episodes/month } \\
<3 \text { Episodes } \\
\geq 3 \text { Episodes }\end{array}$ & $\begin{array}{l}17(81.0) \\
4(19.0)\end{array}$ & $\begin{array}{l}20(60.6) \\
13(39.4)\end{array}$ & 0.117 & $0.498(0.101-2.453)$ \\
\hline $\begin{array}{l}\text { Regularity of routine drugs } \\
\text { Yes } \\
\text { No }\end{array}$ & $\begin{array}{l}17(81.0) \\
4(19.0)\end{array}$ & $\begin{array}{l}29(87.9) \\
4(12.1)\end{array}$ & 0.485 & $0.428(0.070-2.453)$ \\
\hline $\begin{array}{l}\text { Latest PCV } \\
\text { Mild-Moderate anemia } \\
\text { Severe anemia } \\
\end{array}$ & $\begin{array}{l}15(71.4) \\
6(28.6) \\
\end{array}$ & $\begin{array}{l}23(69.7) \\
10(30.3) \\
\end{array}$ & 0.892 & $1.271(0.295-5.470)$ \\
\hline
\end{tabular}

AOR: Adjusted Odds ratio, CI: Confidence Interval 
One of the limitations of this study is that it was a single hospital-based study. A more elaborate community-based or multicenter study may be needed to improve generalization of the findings. Another limitation was that the use of home pain relief was assessed over six months, and as such, the long-term effectiveness of pain relief techniques utilized could not be ascertained.

\section{Conclusions}

This study shows that a substantial number of parents/caregivers employed home pain relief for their children's pain episodes, with majority using multiple pain techniques. A variety of pain relief techniques were used, with the most common drug and CAM being NSAIDs and massage therapy respectively. Most of the parents considered their current home pain management as effective, irrespective of whether single or multiple pain relief techniques were utilized. A higher number of the children with multiple yearly hospitalizations used multiple pain relief techniques.

\section{References}

1. WHO Regional Office for Africa. Sickle-cell disease: a strategy for the WHO African region: report of the regional director (AFR/RC60/68). Geneva, Switzerland: World Health Organization; 2010.

2. Wastnedge E, Waters D, Patel S, et al. The global burden of sickle cell disease in children under five years of age: a systematic review and meta-analysis. J Glob Health 2018;8:021103.

3. Federal Ministry of Health. National guideline for the control and management of sickle cell disease. Nigeria: FMOH 2014; pp. 1-61.

4. Piel FB, Patil AP, Howes RE, et al. Global epidemiology of sickle haemoglobin in neonates : a contemporary geostatistical model-based map and population estimates. Lancet 2013;381:142-51.

5. Piel FB, Hay SI, Gupta S, et al. Global burden of sickle cell anaemia in children under five, 2010-2050: modelling based on demographics, excess mortality, and interventions. PLoS Med 2013;10:e1001484.

6. Inusa BP, Daniel Y, Lawson JO, et al. Sickle cell disease screening in northern Nigeria: the co-existence of BThalassemia inheritance. Pediatr Therapeut 2015;5:262-5.

7. Nwogoh B, Adewoyin A, Iheanacho O, et al. Prevalence of haemoglobin variants in Benin City, Nigeria. Ann Biomed Sci 2012;11:60-4.

8. Diwe K, Iwu AC, Uwakwe K, et al. Prevalence and patterns of sickle cell disease among children attending tertiary and nontertiary health care institutions in a South Eastern State, Nigeria: A 10 year survey. J Res Med Dent Sci 2017;4:183-9.

9. Adewoyin AS. Management of sickle cell disease: a review for physician education in Nigeria (Sub-Saharan Africa). Anemia 2015;2015:7914981.

10. Williams H, Tanabe P. Sickle Cell Disease: A review of nonpharmacological approaches for pain. HHS Public Access 2017;51:163-77.

11. Al-Jafar H, Al-Feeli A, Alozairi A. Non-Conventional pain management for sickle cell disease. Ann Hematol Oncol 2017;4:1161.

12. WHO. WHO guidelines on the pharmacological treatment of persisting pain in children with medical illnesses. 2012. Accessed: Mar 2019. Available from: https://www.ncbi.nlm. nih.gov/books/NBK138354/

13. Mulumba LL, Wilson L. Sickle cell disease among children in Africa: An integrative literature review and global recommendations. Int J Africa Nurs Sci 2015;3:56-64.

14. Nwogoh B, Ofovwe CE, Omoti CE. Health-related quality of life in sickle cell disease subjects in Benin City, Nigeria. Afr J Med Health Sci 2016;15:80-85.

15. Federal Ministry of Health. Guidelines for the management of pain in Nigeria. Nigeria: FMOH 2018; pp. 1-92.

16. National Heart Lung, and Blood Institute. Evidence-based management of sickle cell disease. Expert panel report, 2014. Accessed: Apr 2019. Available from: http://www.nhlbi.nih.gov/sites/www.nhlbi.nih.gov/files/sicklecell-disease-report.pdf

17. Oshikoya KA, Edun B, Oreagba IA. Acute pain management in children with sickle cell anaemia during emergency admission to a teaching hospital in Lagos, Nigeria. S Afr J Child Health 2015;9:119-23.

18. Po C, Colombatti R, Cingliano A, et al. The management of sickle cell pain in the emergency department: a priority for health systems. Clin J Pain 2013;29:60-3.

19. National Bureau of Statistics. Annual abstract of statistics, 2016. Accessed: Mar 2019. Available from: https://www.nigerianstat.gov.ng/pdfuploads/ANNUAL ABSTRACT STATISTICS VOLUME-1.pdf

20. Olusanya O, Okpere E, Ezimokhai M. The importance of social class in voluntary fertility control in a developing country. West Afr J Med 1985;4:205-11.

21. Naing L, Winn T, Rusli BN. Practical issues in calculating the sample size for prevalence studies. Arch Orofac Sci 2006;1:9-14.

22. Hughes E, Jacobs B, Berman BN. In: Tierney L, SJ M, Papadakis $\mathrm{M}$, editors. Complementary and alternative medicine in current medical diagnosis and treatment. McGraw-Hill: 2005; pp. 1696-1719.

23. Sibinga EMS, Shindell DL, Casella JF, et al. Pediatric patients with sickle cell disease: Use of complementary and alternative therapies. J Altern Complement. Med 2006;12:291-8.

24. Yoon SL, Black S. Comprehensive, integrative management of pain for patients. J Altern Complement Med 2006;12:9951001.

25. Busari AA, Mufutau MA. High prevalence of complementary and alternative medicine use among patients with sickle cell disease in a tertiary hospital in Lagos, South West, Nigeria. BMC Complement Altern Med 2017;17:299-306.

26. Majumdar S, Thompson W, Ahmad N, et al. The use and effectiveness of complementary and alternative medicine for pain in sickle cell anemia. Complement Ther Clin Pract 2013;19:184 7.

27. Thompson WE, Eriator I. Pain control in sickle cell disease patients: Use of complementary and alternative medicine. Pain Med 2014;15:241-6.

28. Smith K, Reinman L, Schatz J, Roberts CW. Parent perspectives on pain management in preschool-age children with sickle cell disease. J Pediatr Oncol Nurs 2018;35:16-24.

29. Oshikoya KA, Senbanjo IO, Njokanma OF, et al. Use of complementary and alternative medicines for children with chronic health conditions in Lagos, Nigeria. BMC Complement Altern Med 2008;8:66-73.

30. Ahmadi M, Ilkhani M, Beiranvand S, et al. Massage for pain management in patients with sickle cell disease: a review study. J Chronic Dis Care 2018; 7:e62315. 